\title{
AVALIAÇÃO DA VIABILIDADE DE SEMENTES DE Brachiaria brizantha (Hochst. ex A. Rich) Stapf PELO TESTE DE TETRAZÓLIO
}

\author{
MARIA CRISTINA LEME DE LIMA DIAS ${ }^{1}$, SÉRGIO JOSÉ ALVES²
}

\begin{abstract}
RESUMO - As sementes de Brachiaria brizantha apresentam dormência, principalmente quando recém colhidas, o que torna o teste de germinação ineficiente para avaliar a viabilidade, sendo necessária a realização do teste de tetrazólio. Visando comparar as metodologias mais utilizadas na condução do teste de tetrazólio nestas sementes, determinou-se a viabilidade de quatro lotes da cultivar Marandu, com diferentes qualidades fisiológicas e intensidades de dormência, em cinco épocas trimestrais. O teste de tetrazólio foi conduzido com as seguintes concentrações de 2,3,5 trifenil cloreto tetrazólio: 1,0\% (conforme metodologia prescrita pela International Seed Testing Association - ISTA); $0,2 \%$ e $0,1 \%$ (sem descarte de uma metade da semente). Como teste referencial foi realizada a germinação sem e com tratamento para superar a dormência, utilizando a escarificação em ácido sulfúrico. Os resultados dos testes de tetrazólio obtidos com as menores concentrações não diferiram da metodologia recomendada pela ISTA, mas facilitaram a interpretação, devido a melhor visualização da estrutura embrionária. O tratamento para superação da dormência não foi eficiente para todas as sementes e prejudicou a germinação das não dormentes. Os testes de tetrazólio e de germinação podem ser considerados como complementares e, em conjunto, permitem avaliar a qualidade fisiológica das sementes de Brachiaria brizantha.
\end{abstract}

Termos para indexação: germinação, dormência, viabilidade de sementes.

\section{EVALUATION OF THE Brachiaria brizantha (Hochst.ex A.Rich) Stapf SEEDS VIABILITY THROUGH THE TETRAZOLIUM TEST.}

\begin{abstract}
The Brachiaria brizantha seeds present dormancy mainly just after harvest and, therefore, the germination test is inefficient to evaluate its viability becoming necessary the evaluation with the tetrazolium test. To evaluate the more common methodologies of the tetrazolium test, four groups of the cultivar Marandu seeds, with different physiological qualities and dormancy intensities had its viability evaluated in five three months periods from May 1998 to September 1999. The tetrazolium test was carried on with the following 2,3,5 triphenyl tetrazolium chloride salt concentrations: $1,0 \%$ as prescribed by the International Seed Testing Association (ISTA), $0,2 \%$ and $0,1 \%$ (without discharging half of the seeds). As references the germination test were used with and without treatments to avoid dormancy using scarification with sulfuric acid. The results of the tests with 0,2 and $0,1 \%$ of tretazolium did not differ from the results of the ISTA recommended concentration and had easier interpretation because of better embryo structure visualization. The treatments to suppress the dormancy were not efficient for all seeds and damaged the non-dormant ones. The germination and tetrazolium tests may be considered complementary and together are efficient to evaluate the physiologic quality of Brachiaria brizantha seeds.
\end{abstract}

Index terms: germination, dormancy, seed viability.

${ }^{1}$ Enviado em 25/07/2005. Aceito em 20/08/2008.

${ }^{2}$ Engenheira Agrônoma, Pesquisadora em Tecnologia de Sementes do Instituto Agronômico do Paraná - IAPAR. Caixa Postal 481. 86001-970. Londrina, PR, Brasil. Email: mariacri@iapar.br
${ }^{3}$ Engenheiro Agrônomo, Pesquisador em Genética e Melhoramento Vegetal do Instituto Agronômico do Paraná - IAPAR.

Caixa Postal 481.96001-970. Londrina, PR, Brasil. Email: sja@iapar.br 


\section{INTRODUÇÃO}

O Brasil é o maior produtor, consumidor e exportador mundial de sementes de Brachiaria $s p$. Nas duas últimas décadas tem sido notável o aumento da área de pastagens formadas com gramíneas do gênero Brachiaria, acompanhado de um aumento proporcional na produção e comercialização de suas sementes (Martins e Lago, 1996). Diversos agentes interagem nesse processo de produção, que representa um faturamento de milhões de dólares anualmente e a manutenção de milhares de empregos. Apesar da grande importância, a qualidade das sementes produzidas destas espécies é variável e os investimentos em pesquisa nesta área são escassos.

Toledo (1994) cita que as informações das análises de laboratório são indispensáveis em todas etapas do processamento porque determinarão o destino dos diferentes lotes. Em Brachiaria, entretanto, não raro, as decisões quanto à aquisição de lotes, são baseadas na intuição e/ou experiência do comprador ou mesmo no preço das sementes, pois o período de germinação dessas espécies varia, geralmente, de 15 a 28 dias (Marcos Filho et al., 1987).

Uma correta determinação da qualidade de um lote de sementes de Brachiaria é fundamental, servindo de referência tanto para determinação de seu valor comercial quanto para a implantação de áreas de pastagens.

O teste de germinação padrão vinha sendo utilizado para fins de fiscalização até o final dos anos 90 e freqüentemente gerava problemas, devido à metodologia e interpretação dada pelos diferentes analistas. Utilizar ou não um método de quebra de dormência, considerar ou não como viáveis as sementes firmes presentes no final do teste, são dúvidas comumente encontradas. Além disto, muitos ressaltavam a necessidade de que métodos mais rápidos para a avaliação da qualidade eram necessários para facilitar e acelerar o processo de comercialização.

Segundo a International Rules for Seed Testing da International Seed Testing Association - ISTA (2004), o teste topográfico de tetrazólio é um teste bioquímico para a viabilidade, cujos objetivos são: executar uma estimativa rápida da viabilidade de amostras de sementes em geral e, em particular, naquelas que demonstram dormência; e, no caso de determinadas amostras que ao final do teste de germinação revelam uma alta porcentagem de sementes dormentes, determinar a viabilidade individual das sementes dormentes ou a viabilidade de uma amostra de trabalho.

O teste de tetrazólio estima a viabilidade das sementes em menos de 24 horas, com base na alteração da coloração dos tecidos vivos, em presença de uma solução incolor do 2,3,5 trifenil cloreto ou brometo tetrazólio, usada como indicador para revelar os processos de redução que acontecem dentro das células vivas. $\mathrm{O}$ indicador é absorvido pela semente. Dentro dos tecidos da semente interage com os processos de redução das células vivas e recebe íons hidrogênio das desidrogenases. Através da hidrogenação do 2,3,5 trifenil cloreto tetrazólio, uma substância vermelha, estável e não difusível, o formazan, é produzida nas células vivas. Isto torna possível distinguir as partes vivas coloridas de vermelho. das mortas, que não se colorem. Porém, não possibilita ter maiores informações sobre a porcentagem de sementes dormentes e nem sobre contaminação de patógenos.

Existem diferenças nas metodologias utilizadas nos Laboratórios de Análise de Sementes para a condução do teste de tetrazólio em sementes de Brachiaria sp.; dentre as mais utilizadas estão recomendada pela ISTA: descarte de metade da semente e imersão em solução de tetrazólio a 1,0\%; a utilizada pelos Laboratórios de Análise de Sementes e pelos produtores de sementes no Brasil: descarte de metade da semente e uso de solução de tetrazólio a 0,2\%; e também, a avaliação das duas metades da semente que permanecem unidas pela lema e pálea, após imersão em solução de tetrazólio a $0,1 \%$.

Os materiais utilizados neste teste são relativamente simples, porém, o valor de aquisição do saléum pouco elevado, dessa maneira, é desejável metodologias mais econômicas para realização do teste. Martins e Silva (2001) realizaram o teste de tetrazólio utilizando solução à concentração de $0,075 \%$, a $40^{\circ} \mathrm{C}$, por quatro horas, seguindo-se o esquema de coloração encontrado em Delouche et al., 1976. Usberti e Ortolani, 1975 aplicaram o teste de tetrazólio em sementes de capim-colonião, utilizando quatro repetições de 50 sementes puras, as quais foram colocadas inicialmente durante 12 a 14 horas, sobre papel de germinação umedecido, sendo, em seguida, cortadas longitudinalmente, com uma lâmina, colocando-se uma das metades em recipiente contendo a solução de tetrazólio a $0,1 \%$. As sementes permaneceram em temperatura ambiente durante 6 a 8 horas, quando atingiram a coloração para a avaliação.

O teste de tetrazólio pode ser utilizado na determinação da quantidade de sementes dormentes de braquiária presentes no final do teste de germinação, melhorando o nível de informação da qualidade do lote (Castro et al., 1994; Previero et al., 1998; Martins e Silva, 2001; Dias e Alves, 2000, 2001).

O teste de germinação é um método direto de avaliação da qualidade da semente, pois possibilita observar quais 
sementes deram origem a uma plântula normal em condições favoráveis. Porém, é um teste demorado, necessitando de 21 dias para a obtenção dos resultados (Brasil,,1992), o que dificulta as relações comerciais entre produtores de sementes, comerciantes e pecuaristas. Outra limitação é que ele pode não informar com exatidão a quantidade de sementes dormentes, pois, muitas vezes, os tratamentos para superar a dormência podem não ser totalmente efetivos para a superação desta e ainda prejudicar a germinação de parte das sementes. Segundo Martins e Silva (2001), a escarificação química, método redutor de dormência usado na maioria dos lotes comercializados nas exportações, apresenta riscos operacionais aos trabalhadores, polui o ambiente, e, além disso, pode promover danos qualitativos às sementes.

Visando avaliar as metodologias mais utilizadas na condução do teste de tetrazólio em sementes de Brachiaria brizantha, procurou-se avaliar lotes de sementes com diferentes qualidades iniciais e intensidade de dormência durante o armazenamento.

\section{MATERIAIS E MÉTODOS}

O experimento foi realizado no Laboratório de Análise de Sementes do Instituto Agronômico do Paraná - IAPAR em cinco avaliações trimestrais entre maio de 1998 a setembro de 1999. Foram utilizados quatro lotes de sementes comerciais de Brachiaria brizantha cv. Marandú. Os testes realizados em laboratório foram tetrazólio e germinação sem e com quebra de dormência. $\mathrm{O}$ tratamento para superar a dormência foi a escarificação química em ácido sulfúrico concnetrado por 15 minutos (Brasil, 1992). Inicialmente, foi realizada a análise de pureza nos quatro lotes, de forma a obter sementes puras para as amostras/repetições/épocas de todo o experimento. As amostras foram acondicionadas em sacos de papel multifoliado e armazenadas em condições de ambiente.

Para realização do teste de tetrazólio, foram utilizadas três metodologias de avaliação: solução de tetrazólio à concentração $1,0 \%$ (ISTA, 2004), com descarte de metade da semente; solução de tetrazólio a $0,2 \%$, com descarte de metade da semente; e, solução a $0,1 \%$, sendo mantida as duas partes da cariopse ligadas pela lema e pálea Dias e Barros (1995). Cada amostra foi dividida em quatro repetições de 50 sementes. As sementes foram pré- umedecidas, em papel toalha durante 16 horas em germinador a $30^{\circ}$ C. Posteriormente, foram cortadas longitudinalmente e medianamente através do embrião, sendo ou não descartadas metade das sementes, de acordo com a metodologia adotada. Cada repetição foi imersa em solução de tetrazólio dentro de copos plásticos e mantidas em câmara escura à temperatura de $37^{\circ} \mathrm{C}$ por três horas. Após este período, as soluções foram descartadas, as sementes lavadas em água corrente e as amostras foram avaliadas conforme a coloração adquirida de cada semente, sendo classificadas como viáveis ou não viáveis, de acordo com os critérios para sementes de milho em Dias e Barros (1995).

O teste de germinação foi realizado sem e com tratamento para quebrar a dormência, conforme as prescrições das Regras para Análise de Sementes (Brasil, 1992). Para superar a dormência os tratamentos utilizados foram: escarificação com ácido sulfúrico $\left(\mathrm{H}_{2} \mathrm{SO}_{4}\right)$ - as sementes foram imersas em ácido sulfúrico por 15 minutos e depois foram lavadas em água corrente durante 2 horas; e tratamento térmico, expondo as sementes à $42^{\circ}$ durante 72 horas. As amostras foram divididas em quatro repetições de 50 sementes, instaladas em gerbox sobre papel filtro qualitativo $(250 \mathrm{~g} / \mathrm{m} 2)$ umedecido, e levadas para germinadores, previamente regulados à temperatura de $20-35^{\circ} \mathrm{C}$, com luz. Aos 7,14 e 21 dias foram feitas às avaliações das plântulas normais. Após o teste de germinação as sementes dormentes remanescentes ou firmes foram separadas visualmente das mortas e contadas.

$\mathrm{O}$ delineamento experimental foi inteiramente casualizado com quatro repetições em esquema fatorial $5 \times 4 \times 5$ (tratamento x lote x época). Efetuou-se análise de variância e teste de comparação de médias de Tukey, utilizando-se o programa estatístico Sisvar ${ }^{\circledR}$ (Ferreira, 2000).

\section{RESULTADOS E DISCUSSÃO}

Os efeitos (época, lote e tratamento) e as interações época $\mathrm{x}$ lote, época $\mathrm{x}$ tratamento, lote $\mathrm{x}$ tratamento, época $\mathrm{x}$ lote $\mathrm{x}$ tratamento foram significativas $(\mathrm{P}<0,0001)$. A analise dos resultados permitiram inferir que os lotes diferem consideravelmente entre si.

Na Tabela 1 observa-se que o lote 1 apresentava alta viabilidade inicial e que foi diminuindo com o tempo de armazenamento, conforme os resultados de viabilidades obtidos com as três metodologias do teste de tetrazólio avaliadas (TZ 0,1\%; TZ 0,2\% e TZ 1\%). A germinação sem quebra (\%G SQ) inicial deste lote é baixa, indicando alto nível de dormência e como esperado vai sendo superada com o passar do tempo e chegando a não diferir dos resultados de TZ 0,2\% e TZ 1\%, encontrados após 16 meses de armazenamento . $\mathrm{O}$ tratamento de germinação com quebra de dormência ( $\left.\% \mathrm{G} \mathrm{H}_{2} \mathrm{SO}_{4}\right)$ diferiu significativamente 
da germinação sem quebra nas três primeiras épocas de avaliação e também na última época. Ambos os tratamentos diferiram dos testes de tetrazólio (TZ 0,1\%; TZ 0,2\% e TZ $1 \%$ ). em todas as épocas analisadas. Ou seja, o tratamento com ácido sulfúrico $\left(\% \mathrm{G} \mathrm{H}_{2} \mathrm{SO}_{4}\right)$ foi apenas parcialmente efetivo na quebra de dormência das sementes nas três épocas iniciais de avaliação e prejudicou a germinação quando esta já havia sido naturalmente superada, na ultima época.

TABELA 1. Resultados médios (\%) dos testes de germinação sem quebra de dormência (\%G SQ) e com quebra de dormência com ácido sulfúrico $\left(\% \mathrm{G} \mathrm{H}_{2} \mathrm{SO}_{4}\right)$ e de tetrazólio avaliado por três metodologias: TZ 0,1\%, 0,2\% e 1,0\%, no Lote 1 de Brachiaria brizantha cv. Marandú em cinco épocas de análise. IAPAR, Londrina, 2000.

\begin{tabular}{cccccc}
\hline ÉPOCAS & $\% \mathrm{G} \mathrm{SQ}$ & $\% \mathrm{G} \mathrm{H} 2 \mathrm{SO} 4$ & TZ 0,1\% & TZ 0,2\% & TZ 1,0\% \\
\hline $1^{\mathrm{a}}$ & $13,50 \mathrm{Cc}$ & $30,00 \mathrm{Cb}$ & $86,25 \mathrm{Aa}$ & $91,25 \mathrm{Aa}$ & $84,25 \mathrm{Aa}$ \\
$2^{\mathrm{a}}$ & $14,00 \mathrm{Cc}$ & $43,75 \mathrm{Bb}$ & $85,00 \mathrm{Aa}$ & $88,50 \mathrm{ABa}$ & $84,25 \mathrm{Aa}$ \\
$3^{\mathrm{a}}$ & $51,75 \mathrm{Bc}$ & $64,50 \mathrm{Ab}$ & $83,00 \mathrm{Aa}$ & $81,00 \mathrm{BCa}$ & $82,25 \mathrm{Aa}$ \\
$4^{\mathrm{a}}$ & $63,25 \mathrm{Ab}$ & $64,25 \mathrm{Ab}$ & $81,75 \mathrm{Aa}$ & $82,25 \mathrm{ABCa}$ & $82,75 \mathrm{Aa}$ \\
$5^{\mathrm{a}}$ & $71,25 \mathrm{Ab}$ & $52,75 \mathrm{Bc}$ & $81,25 \mathrm{Aa}$ & $74,25 \mathrm{Cab}$ & $77,75 \mathrm{Aab}$ \\
\hline
\end{tabular}

*Médias seguidas pela mesma letra não diferem estatisticamente entre si, maiúscula na coluna e minúscula na linha. Tukey a 5\% de probabilidade.

O lote 2 (Tabela 2) apresentou alta viabilidade inicial , conforme os resultados das três metodologias do teste de tetrazólio avaliadas (TZ 0,1\%; TZ 0,2\% e TZ 1\%). A germinação sem quebra $(\% \mathrm{G} \mathrm{SQ})$ foi inicialmente superior à observada para o lote 1 , sendo porém inferior ao observado para este lote nas duas últimas épocas de avaliação. $\mathrm{O}$ ácido sulfúrico foi parcialmente efetivo na quebra de dormência nas duas primeiras épocas de avaliação, efetivo na terceira época e pouco efetivo nas duas últimas épocas. À partir dos resultados observados neste lote e no lote 1 e considerando que um lote é formado por milhares de sementes que podem ter variações em intensidades de dormência, aparentemente o ácido sulfúrico passou a prejudicar as sementes não dormentes nas avaliações das duas ultimas épocas. Para este lote, observaram-se pequenas diferenças entre os testes de tetrazólio. Os valores observados nas épocas iniciais para os tratamentos com maiores concentrações de tetrazólio (TZ $0,2 \%$ e TZ 1,0\%) indicam uma maior dificuldade de avaliação da viabilidade em sementes com as maiores concentrações do sal e com o descarte de metade das sementes. Sementes de Brachiaria com menor nível de dormência têm tecidos mais permeáveis a penetração da solução de tetrazólio, colorindo-se mais intensamente e dificultando a visualização topográfica das estruturas e a avaliação.

TABELA 2. Resultados médios (\%) dos testes de germinação sem quebra de dormência (\%G SQ) e com quebra de dormência com ácido sulfúrico (\% $\left.\mathrm{G} \mathrm{H}_{2} \mathrm{SO}_{4}\right)$ e de tetrazólio avaliado por três metodologias: $\mathrm{TZ}$ 0,1\%, 0,2\% e 1,0\%, no Lote 2 de Brachiaria brizantha cv. Marandú em cinco épocas de análise. IAPAR, Londrina, 2000 .

\begin{tabular}{clllll}
\hline ÉPOCA & G SQ & $\%$ G H2SO4 & TZ 0,1\% & TZ 0,2\% & TZ 1,0\% \\
\hline $1^{\mathrm{a}}$ & $39,25 \mathrm{Cd}$ & $52,75 \mathrm{Bc}$ & $71,25 \mathrm{Ab}$ & $84,00 \mathrm{Aa}$ & $73,25 \mathrm{Ab}$ \\
$2^{\mathrm{a}}$ & $57,75 \mathrm{Ac}$ & $71,50 \mathrm{Ab}$ & $75,50 \mathrm{Aab}$ & $85,25 \mathrm{Aa}$ & $81,50 \mathrm{ACa}$ \\
$3^{\mathrm{a}}$ & $55,75 \mathrm{ABb}$ & $73,75 \mathrm{Aa}$ & $75,25 \mathrm{ACa}$ & $79,00 \mathrm{ABa}$ & $79,00 \mathrm{Aa}$ \\
$4^{\mathrm{a}}$ & $46,00 \mathrm{BCc}$ & $56,50 \mathrm{Bb}$ & $79,00 \mathrm{Aa}$ & $74,00 \mathrm{Ba}$ & $76,25 \mathrm{Aa}$ \\
$5^{\mathrm{a}}$ & $44,75 \mathrm{Cb}$ & $49,75 \mathrm{Bb}$ & $75,75 \mathrm{Aa}$ & $77,25 \mathrm{ABa}$ & $74,50 \mathrm{Aa}$ \\
\hline
\end{tabular}

Na Tabela 3 verifica-se que o lote 3 tinha baixa viabilidade inicial e baixa germinação. O tratamento de quebra de dormência $\left(\% \mathrm{G} \mathrm{H}_{2} \mathrm{SO}_{4}\right)$ não diferiu estatisticamente do sem quebra ( $\% \mathrm{G} \mathrm{SQ})$, mas ambos diferiram, na maioria das épocas avaliadas, dos resultados de viabilidade dos testes tetrazólio (TZ 0,1\%; TZ 0,2\% e TZ 1\%). Em relação ao tetrazólio percebeu-se, conforme anteriormente relatado, uma maior dificuldade na avaliação da viabilidade das sementes com maiores concentrações da solução e com o descarte de metade das sementes, principalmente na avaliação inicial e 
na final, nas quais o tratamento TZ $0,1 \%$ diferiu das maiores concentrações. Quando se tem apenas uma metade da semente pode haver dúvidas quanto à coloração do pequeno embrião desta espécie, pois devido à dificuldade de cortar no meio do eixo embrionário, os tecidos podem se colorir de forma a dificultar a avaliação do analista, ou o dano se localizar na parte descartada. Quando se usou as duas metades da semente, o analista pode fazer a comparação entre as duas metades e informar o resultado com mais certeza, o que pode ter contribuído para maior precisão nos resultados. Além disto, o sal de tetrazólio tem um custo relativamente alto, e a solução a $0,1 \%$ pode tornar o teste mais barato. Dessa maneira esta metodologia atende melhor a esses problemas levantados acima, pois ela propõe a utilização das duas metades da semente e a solução do sal à concentração de $0,1 \%$.

TABELA 3. Resultados médios (\%) dos testes de germinação sem quebra de dormência (\%G SQ) e com quebra de dormência com ácido sulfúrico ( $\left.\% \mathrm{G} \mathrm{H}_{2} \mathrm{SO}_{4}\right)$ e de tetrazólio avaliado por três metodologias: TZ $0,1 \%$, $0,2 \%$ e 1,0\%, no Lote 3 de Brachiaria brizantha cv. Marandú em cinco épocas de análise. IAPAR, Londrina, 2000.

\begin{tabular}{cccccc}
\hline ÉPOCA & $\% \mathrm{G} \mathrm{SQ}$ & $\% \mathrm{G} \mathrm{H} 2 \mathrm{SO} 4$ & TZ 0,1\% & TZ 0,2\% & TZ 1,0\% \\
\hline $1^{\mathrm{a}}$ & $23,00 \mathrm{Ac}$ & $27,50 \mathrm{Abc}$ & $30,00 \mathrm{ABbc}$ & $44,25 \mathrm{Aa}$ & $37,25 \mathrm{ABab}$ \\
$2^{\mathrm{a}}$ & $20,00 \mathrm{ABb}$ & $28,25 \mathrm{Ab}$ & $38,25 \mathrm{Aa}$ & $46,00 \mathrm{Aa}$ & $45,00 \mathrm{Aa}$ \\
$3^{\mathrm{a}}$ & $21,00 \mathrm{ABb}$ & $27,25 \mathrm{Aab}$ & $31,25 \mathrm{Aba}$ & $36,75 \mathrm{ABa}$ & $34,50 \mathrm{BCa}$ \\
$4^{\mathrm{a}}$ & $9,50 \mathrm{Cb}$ & $14,25 \mathrm{Bb}$ & $27,50 \mathrm{BCa}$ & $30,00 \mathrm{Ba}$ & $26,00 \mathrm{Ca}$ \\
$5^{\mathrm{a}}$ & $12,00 \mathrm{BCb}$ & $10,00 \mathrm{Bb}$ & $19,50 \mathrm{Cb}$ & $32,75 \mathrm{Ba}$ & $33,00 \mathrm{BCa}$ \\
\hline
\end{tabular}

*Médias seguidas pela mesma letra não diferem estatisticamente entre si, maiúscula na coluna e minúscula na linha. Tukey a 5\% de probabilidade.

O lote 4 (Tabela 4) apresentou alta viabilidade inicial e níveis intermediários de germinação. A germinação com quebra (\%G H2SO4) diferiu da sem quebra (\%G SQ) apenas na segunda época de avaliação, as quais por sua vez diferiram das avaliações com tetrazólio nas quatro primeiras épocas. Na última época de avaliação apenas os resultados da viabilidade com a menor $(0,1 \%)$ e a maior
$(1,0 \%)$ concentração de tetrazólio apresentaram diferenças significativas. Ou seja, aparentemente a dormência inicial existente foi sendo parcialmente superada durante o armazenamento, concomitantemente com a perda de viabilidade de parte das sementes do lote. O tempo possível de armazenamento deste lote seria aparentemente menor do que os dos lotes 1 e 2 .

TABELA 4. Resultados médios (\%) dos testes de germinação sem quebra de dormência (\%G SQ) e com quebra de dormência com ácido sulfúrico (\% $\left.\mathrm{G} \mathrm{H}_{2} \mathrm{SO}_{4}\right)$ e de tetrazólio avaliado por três metodologias: TZ $0,1 \%$, 0,2\% e 1,0\%, no Lote 4 de Brachiaria brizantha cv. Marandú em cinco épocas de análise. IAPAR, Londrina, 2000.

\begin{tabular}{cccccc}
\hline ÉPOCA & $\% \mathrm{G} \mathrm{SQ}$ & $\% \mathrm{G} \mathrm{H} 2 \mathrm{SO} 4$ & $\mathrm{TZ} \mathrm{0,1 \%}$ & $\mathrm{TZ} \mathrm{0,2 \%}$ & $\mathrm{TZ} \mathrm{1,0 \%}$ \\
\hline $1^{\mathrm{a}}$ & $34,50 \mathrm{BCb}$ & $44,25 \mathrm{Ab}$ & $74,50 \mathrm{Aa}$ & $78,50 \mathrm{Aa}$ & $74,50 \mathrm{Aa}$ \\
$2^{\mathrm{a}}$ & $32,25 \mathrm{Cc}$ & $48,75 \mathrm{Ab}$ & $66,00 \mathrm{Aba}$ & $74,25 \mathrm{Aa}$ & $74,00 \mathrm{Aa}$ \\
$3^{\mathrm{a}}$ & $49,25 \mathrm{Ab}$ & $50,25 \mathrm{Ab}$ & $70,25 \mathrm{Aba}$ & $63,50 \mathrm{Ba}$ & $66,25 \mathrm{Aba}$ \\
$4^{\mathrm{a}}$ & $43,00 \mathrm{ABb}$ & $34,00 \mathrm{Bb}$ & $60,50 \mathrm{Ba}$ & $61,25 \mathrm{Ba}$ & $60,00 \mathrm{Ba}$ \\
$5^{\mathrm{a}}$ & $47,00 \mathrm{Ab}$ & $45,75 \mathrm{Ab}$ & $48,75 \mathrm{Cb}$ & $53,75 \mathrm{Bab}$ & $61,75 \mathrm{Ba}$ \\
\hline
\end{tabular}

*Médias seguidas pela mesma letra não diferem estatisticamente entre si, maiúscula na coluna e minúscula na linha. Tukey a $5 \%$ de probabilidade.

A análise de germinação e tetrazólio dos diferentes lotes e épocas permitiram uma série de considerações. A dormência foi diminuindo com o tempo, porém, com exceção do lote 4 (tabela 4), o tempo de avaliação parece não ter sido 
suficiente para a sua completa superação. A viabilidade das sementes, também diminuiu com tempo, sendo que, somente o lote 2 (Tabela 2) manteve a viabilidade durante os 16 meses de armazenamento avaliados.

A germinação foi, em todos os lotes e épocas, inferior a viabilidade em tetrazólio, mostrando que apesar de vivas, muitas sementes não germinam devido à dormência. $\mathrm{O}$ teste de tetrazólio mostrou resultados mais uniformes em diferentes épocas, o que é explicado pela variação dos índices de dormência das sementes conforme a época de avaliação.

No teste de germinação, uma das dificuldades encontrada é a identificação das sementes dormentes remanescentes no final do teste, como viáveis ou mortas, o que pode ser solucionado pelo a.uso do tetrazólio,

O tratamento com ácido sulfúrico melhorou a germinação de sementes nos trabalhos realizados por Lago \& Martins (1998) e Garcia \& Cícero (1992). No entanto os resultados obtidos neste trabalho, mostraram que este tratamento pode melhorar ou piorar a germinação das sementes de Brachiaria, como o ocorrido com o Lote 1 na $3^{\mathrm{a}}$ época (Tabela 1), dependendo do estado fisiológico do lote de sementes, e também de que a quebra de dormência é parcial e não chegando a possibilitar a germinação de todas as sementes viáveis. Os diferentes resultados obtidos para os diferentes lotes e épocas indicam que pode ser difícil decidir fazer ou não o tratamento para superação da dormência. $\mathrm{O}$ tratamento com ácido sulfúrico não foi efetivo para a completa superação de dormência, apesar de ter favorecido esta em várias situações (Tabela 1, nas três primeiras épocas; Tabela 2 nas quatro primeiras épocas e Tabela 4, na segunda época), por outro lado, prejudicou a germinação das sementes na quinta época do lote 1 (Tabela 1).

Os resultados do teste de tetrazólio das três metodologias avaliadas foram superiores, em quase todos os lotes e épocas, aos obtidos nos testes de germinação sem (\%G SQ) e com quebra de dormência (G $\mathrm{H} 2 \mathrm{SO} 4$ ), evidenciando que no teste de germinação, mesmo quando se realizou tratamento para quebra de dormência, nem todas as sementes que foram classificadas como viáveis pelo teste de tetrazólio, germinaram.

\section{CONCLUSÕES}

O teste de tetrazólio realizado na concentração $(0,1 \%)$ e com a visualização das duas metades da semente, facilita a interpretação dos resultados, notadamente em lotes com menor viabilidade, além de possibilitar redução de custos.

O tratamento para superação da dormência não é eficiente para todos os lotes e pode prejudicar a germinação das sementes não dormentes, dependendo da qualidade fisiológica do lote.

Os testes de tetrazólio e germinação podem ser considerados como complementares e em conjunto, permitem avaliar a qualidade fisiológica das sementes de Brachiaria brizantha

\section{AGRADECIMENTOS}

Aos funcionários do Laboratório de Análise de Sementes do IAPAR, em especial a Maria Aparecida Dias da Silva, pelas análises e sugestões que muito contribuíram para a realização deste trabalho.

\section{REFERÊNCIAS}

ALMEIDA, C. R. Comportamento da dormência de sementes de Brachiaria dictyoneura cv. Lhanero submetidas às ações do calor e do ácido sulfúrico. 2002. 47f. Dissertação (Mestrado em Fitotecnia) - Escola Superior de Agricultura Luiz de Queiroz, Piracicaba, 2002.

BRASIL, Ministério da Agricultura e Reforma Agrária. Regras para Análise de Sementes. Brasília: SNDA/DNDV/ CLV, 1992. 365p.

CASTRO, C.R.T; CARVALHO, W.L. ; REIS, F.P; BRAGA FILHO, J.M. Influência do tratamento com ácido sulfúrico na germinação de Brachiaria brizantha Stapf. Revista Ceres, Piracicaba, v.41, n.236, p. 451-458, 1994.

DELOUCHE, J.C.; STILL, T.W.; RASPET, M.; LIENHARD, M. O teste de tetrazólio para viabilidade da semente. Brasília: AGIPLAN, 103p. 1976.

DIAS, M.C.L.L.; ALVES, S.J. Avaliação da viabilidade de sementes de Brachiaria brizantha (Hochst. Ex A. Rich) Stapf pelo teste de tetrazólio. In: SEMINARIO PANAMERICANO DE SEMILLAS, 17, p. 133, Punta del Este- Uruguay, 2000.

DIAS, M.C.L.L.; ALVES, S.J. Avaliação da viabilidade de sementes de Brachiaria brizantha (Hochst. Ex A. Rich) Stapf pelo teste de tetrazólio. In: CONGRESSO BRASILEIRO DE SEMENTES, 12, Curitiba, 2001. Informativo Abrates, Londrina, v.11, n. 2, p. 317, 2001.

DIAS, M. C. L. L.; BARROS, A.S.R. Avaliação da qualidade de sementes de milho. Londrina: IAPAR, 1995. 43 p. (IAPAR. Circular, 88).

FERREIRA, D.F. Análises estatísticas por meio do Sisvar para Windows versão 4.0. In... REUNIÃO ANUAL DA REGIÃO BRASILEIRA DA SOCIEDADE INTERNACIONAL DE 
BIOMETRIA, 45, 2000. Anais... São Carlos: SIB, p. 255$258,2000$.

GARCIA, J.; CÍCERO, S.M. Superação de dormência em sementes de Brachiaria brizantha cv. Marandu. Scientiae Agricola, Piracicaba, v.49, n.1, p. 9-13, 1992.

INTERNATIONAL SEED TESTING ASSOCIATION. International Rules for Seed Testing. Seed Science and Technology, Edition 2004. 2004.

LAGO, A. A.; MARTINS, L. Qualidade fisiológica de sementes de Brachiaria brizantha. Pesquisa Agropecuária Brasileira, Brasília, v.33, n.2, 1998.

MARCOS FILHO, J.; CICERO, S.M.; SILVA, W.R. Avaliação da qualidade das sementes. Piracicaba: FEALQ, 1987. 230p.

MARTINS, L.; LAGO, A.A. Germinação e viabilidade de sementes de Brachiaria brizantha (Hochst. Ex A. Rich) Stapf durante o armazenamento. Revista Brasileira de Sementes,
Brasília, v.18, n.2, p. 262-266, 1996.

MARTINS, L.; SILVA, W. R.; Comportamento da dormência em sementes de braquiária submetidas a tratamentos térmicos e químicos. Pesquisa Agropecuária Brasileira, Brasília, v.36, n.7, p. 997-1003, 2001.

PREVIERO, C.A.; GROTH, D.; RAZERA, L.F. Dormência de sementes de Brachiaria brizantha (Hochst. Ex A. Rich) Stapf armazenadas com diferentes teores de água em dois tipos de embalagens. Revista Brasileira de Sementes, Brasília, v.20, n.2, p. 392-397, 1998.

TOLEDO, F.F. Processamento e conservação de sementes de forrageiras In: PEIXOTO, A.M.; MOURA, J.C.; FARIA, V.P. Pastagens fundamentos da exploração racional. Piracicaba: FEALQ, 1994, p. 867 - 877.

USBERTI, R.; ORTOLANI, D.B. Aplicação do teste de tetrazólio em sementes de capim colonião (Panicum maximum Jacq.). Científica, Jaboticabal, v.3, n.2, p.355356, 1975. 